\title{
Editorial
}

\section{Lest we forget}

A few weeks ago we had a royal occasion at my hospital, and the paediatricians were lined up in their best suits; surprised, cleaned shoes; and brushed down hair ready to be presented to the royal person. She had come to open formally the new purpose built accommodation for families to stay while their ill child was being treated in our children's unit. I could not help thinking back to the times of 15 or 20 years ago when parental access to children in hospital was so limited. The very fact that a prime site in our hospital grounds had been used for this building, and that despite financial cut backs and worries about the running costs, the proposals had been accepted by the various committees and executive of a very large acute general hospital, confirmed that the need for parents to have unlimited access to their ill children was accepted. There had been conflicting demands-for a new oncology clinic, for a nuclear magnetic resonance scanner, and other high technology developments, but though there had been some argument about the order of priorities, there were neither medical nor administrative colleagues who doubted that such a residential unit in a hospital which accepted children from a long way away was needed for the child and the family's welfare.

Those of us in senior positions today must be grateful to our former teachers and leaders who made this change of opinion and new acceptance possible. But are we in our turn doing enough to preserve this right for children, and in teaching our juniors and trainees about the issues that Bowlby and Spitz raised 40 years ago? I worry about this when I visit a hospital at which someone who has trained with me is now a consultant paediatrician, and which has negligible facilities for mothers to stay with their ill child in hospital or which has restrictions on parental visiting on the day of operation and sometimes other days each week. I feel even more guilty when I go to a third world country: visit the children's wards there and you find that the parents are allowed to visit for only one hour twice a week. These countries, at times, seem to be putting their resources into monuments for high technology paediatrics and losing that which a few years ago they had-parents nursing and caring for their own children. Is it absolutely necessary for them to go through the same painful process that industrialised countries had of a prolonged period in which parents were banned from being with their ill children? Yet, once again, those of influence in these overseas units have often been trained in Western countries-I feel ashamed when an overseas trainee seems to have learnt merely the techniques of dialysis from me and little else; the fault is mine not theirs. How often do we in our postgraduate and in-service training discuss the problems of children in hospital, their psychological needs and the needs and the problems of unrestricted access for parents? Many of us take it for granted and fail to pass on the message, yet it is a message that can be discussed more critically and pertinently today than ever before.

It is easy to criticise some of the detailed findings of John Bowlby in relation to long term harm to children occurring as a result of separation in early life from their parents, and to point to the greater importance of other coincidental adverse factors. Moreover, we can read the follow up study which Archives published last September from Christchurch, New Zealand purporting to show that children treated in that Christchurch hospital in 1970 did not show adverse effects later in life; but that is a reflection of the skill with which the Christchurch workers have created an environment which does not seem to harm children: the fact remains that admission to hospital for a child is often unpleasant and frightening, and can be dangerous.

Twenty years ago there appeared a brief article written by two paediatricians who were in the vanguard establishing better conditions for children in hospital and rights for parents to visit and be with them. The article, which is reprinted on page 179 , was vivid and effective propaganda at the time and made some of us who were then junior doctors wonder for the first time if it was possible for a child to die from unhappiness. We should ask our trainees to read it today and tell us what they think. 